$5^{\text {th }}$ January $2011-$ Revised $8^{\text {th }}$ May 2011

\title{
GOVERNANCE OF LONDON 2012 OLYMPIC GAMES LEGACY
}

\begin{abstract}
This study addresses the governance of London 2012 Olympics legacy. It presents legacy not as a retrospective but a prospective concept concerned with shaping the future through interactions between the state, market and society. This entails designing systems of governance to guide and steer collective actions towards a consensus amongst various parties concerned. Four modes of governance and a range of policy instruments were examined in the delivery of sustainable London Olympics sport legacy including coercive, voluntarism, targeting and framework regulation. The British government actively created a new policy space and promoted institutional conduct consistent with its legacy visions. The current global legacy framework is lacking the governance dimension and its logic needs to be reconsidered. A meaningful sport legacy requires not top-down approaches but locally informed strategies supported by a developmental design of the Olympic Games informed by sustainable principles.
\end{abstract}

Key words: governance, legacy, policy analysis, Olympic Games, sustainable sports development 


\section{Governance of London 2012 Olympic Games legacy}

This paper examines the construction of the 2012 London Olympics sport legacy as a governance issue. The concept of Olympic sporting legacy has been gaining currency, but partly due to the retrospective nature of academic writing, and partly because of the etymology of the word legacy meaning "an individual bequest or anything that is left over from an event" (Cashman, 2006: 15), it has been couched in past tense language through the repetitive use of terms such as 'what is left after the Olympic Games'. What tends to be overlooked is the fact that legacy is a prospective concept. In answering the question 'What we mean by legacy?' the UK Government stated (DCMS, 2008: 8):

The 'legacy' of the London 2012 Games refers to the imprint they leave. It is therefore not just what happens after the Games, but what we do before and during them to inspire individuals and organizations to strive for their best, to try new activities, forge new links or develop new skills.

This statement presents Olympic legacy (OL) as essentially a forward thinking exercise with clear developmental goals performing a range of political, economic and social functions. The construction of Olympic legacy, therefore, represents a developmental project which holds both a promise to accomplish something that does not exist and the uncertainty of how this future state is going to be delivered. As Horne and Manzenreiter (2006, p. 9) observed "the 'legacies' - whether social, cultural, environmental, political, economic or sporting - are the greatest attraction but also form part of the 'known unknowns' of sports mega-events". 
The UK Government undertook the ambitious task of ensuring a UK wide legacy of the 2012 Games formulated in six specific promises and a comprehensive delivery strategy (DCMS, 2008). The UK Government's approach to the Games' legacy was in line with its sustainable strategy (HM Government, 2007) and followed two main thrusts - its own use of sport as a solution to social problems ('sport for good', Collins, 2010) and the contractual obligations that come with the rights to host the Olympics. Since the beginning of the 2000s the International Olympic Committee (IOC) has added developmental assurances, as well as promoting a positive legacy, to the political, economic and security guarantees, required by governments wishing to host the Olympics (IOC, 2007). The above thrusts are indicative of a changing polity where state, market, non-state and global actors are involved in social steering.

While the link between hosting the Olympics and urban governance has been established in the literature (Newman, 2007, Shoval, 2002), most studies on mega sporting events have failed to explicitly recognize the legacy construction process as a governance issue. The delivery of any social, economic or sporting legacy entails designing systems of governance to guide and steer collective actions towards a consensus amongst various parties concerned. More specifically, this paper interrogates the modes of governance of the London Games sustainable sport legacy. The study therefore, contributes to the literature on sport governance (Chappelet \& Kübler-Mabbott, 2008, Henry, 2007, Hoye, 2007, Hums \& MacLean, 2004) and Olympic governance (Brubank, Andranovich \& Heying, 2001, Cashman, 2006, Leopkey, 2009, Owen, 2001, Poynter \& MacRury, 2009) by theorizing the state-society relations as a result of OL construction. 
The first part of the paper offers an interpretation of governance as a theoretical idea, a normative concept and an empirical phenomenon that will be used to inform the analysis. The second part unpacks the changing polity of Olympic legacy by analyzing the emerging institutional arrangements resulting from the exchange between the state and society in the form of the UK Government's promises. The third part deals with the politics of Olympic legacy governance. Finally, the governance of the 2012 London Olympics sustainable sport legacy is analyzed as policy (i.e., an empirical phenomenon).

\section{Governance and Olympic legacy}

Olympic legacies have been variously conceptualized (Girginov \& Hills, 2009, Holden et al, 2009, MacAloon, 2008, MacRury, 2008, Preuss, 2007, Roche, 2009). However, most commentators agree that apart from the positive energy, creativity and long-term infrastructural improvements which the Olympics can bring to the host city and country, the Games serve as a source of negative development as well. It is this tension between what is being done in the name of legacy, for whom, at what cost and to what effect that turns Olympic legacy into a governance issue, as a central element of democratic polity.

Increasingly, the Olympic legacy discourse and practical policies have also been framed within the notion of sustainable development (Frey at al, 2007, Furrer, 2002, Holden et al, 2008, IOC, 2009, Smith, 2007). Sustainability has become a global attractor and a point of directionality (Mol, 2010), which brings a whole new dimension to the conceptualization and delivery of mega events legacy and turns it into a governance issue. This is because at the heart of sustainability is an expressed concern with meeting 
the needs of different people while distributing social and economic benefits equally and fairly across society (Dressner, 2003). As Boron \& Murray (2004) noted, sustainability represents a paradigm shift in reconfiguring the balance between the three environmental, economic and social domains in decision making. Spangenberg (2004) also argued for integrated politics taking into account the economic, environmental, social and institutional dimensions of sustainability. However, as Short (2008: 332) remarked existing analyses suggest that the distribution of costs and benefits is regressive with most of the cost borne locally, especially by the more marginal urban residents displaced to make way for the Games, while most of the benefits accrue to local elites and a global media market.

The construction of Olympic legacy therefore, provides a new policy space where old and new actors interact in order to negotiate the meaning of legacy and how particular visions of it are to be achieved. The involvement of the UK Government in shaping the legacy of the 2012 London Games provides an informative example for the governmentalization of new spheres of state activity.

This study builds on four comprehensive reviews of the key meanings of governance, which are commonly shared although under different names (Jordan, 2008, Peters \& Pierre, 1998, Rhodes, 2007, Treib, Bähr \& Falkner, 2007). Those meanings explain governance in terms of a political theory, describing a certain type of exchange between the state and society; a process of steering concerned with "enhancing government's capacity to act by forging strategic organizational coalitions with actors in the external environment” (Peters \& Pierre, 1998: 231); and an empirical phenomenon concerning the deployment of specific policy instruments. 
In analyzing governance, Treib et al (2007) made a useful distinction between its institutional properties (polity), actor constellations (politics), and policy instruments (policy) which broadly correspond with the above meanings, but offer greater detail and analytical power. Focusing on the institutional properties of the state is important, as Hardman \& Scott (2010: 171) argued, because "the changing profile of state agencies has implications for our understanding of the range of state responsibilities and how they are managed". In order to understand governance as politics we need to attend to actor constellation and power relation between political actors. Governance in this case, as Rhodes (2007: 1246) noted, "refers to governing with and through networks". Taken as policy, governance implies attending to the mode of political steering, or the use of a range of policy instruments such as regulations, norms and sanctions. Treib et al (2007) proposed four such modes of governance in the policy dimension including coercion, voluntarism, targeting and framework regulation. Coercion "is characterized by binding legal instruments prescribing detailed and fixed standards that leave little leeway in implementation" (p.14). In contrast, voluntarism is based on non-binding guidelines and only defines broad goals that actors may specify in implementation. Targeting "also uses non-binding recommendations, but these recommendations are more detailed and thus leave less room for manoeuvre for specification at the implementation stage than is true in the case of voluntarism" (p.15). Finally, similar to coercion, framework regulation relies on binding law but it offers participants more leeway in implementation. Those four modes will be used to examine the governance of sustainable Olympic sport legacies. 
Governance is also a normative concept. It reflects the essence of the London Olympics which were conceived and being delivered as a sustainable developmental project permeating the thinking and practices of all institutions and individuals involved (LOCOG, 2009). The UK Government reiterated its commitment to deliver a sustainable Games in its Olympic Action Plan (DCMS, 2008). The Olympic Games legacy, as intended development and a normative concept, has been argued by Girginov \& Hills (2008). The important point is that sustainable development, as Jordan (2008: 25) noted, is "at root, a fundamental normative idea and a great deal of effort has been expended to trying to identify what governance changes are needed to put it into effect".

\section{Research design}

This study utilized a qualitative policy research design. It follows a lead proposed by Ritchie and Spencer (2002) who argued that typically the questions addressed in policy studies can be divided into four categories: contextual-identifying the form and nature of what exists; diagnostic-examining the reasons for, or causes of, what exists; evaluative-appraising the effectiveness of what exists, and strategic-identifying new theories, policies, plans or actions. In particular, the study focused on contextual, diagnostic and evaluative questions, thus bridging between the conceptualization of governance as polity, policy and politics and its operationalization. The main contextual questions addressed were 'who are the legacy actors operating on the Olympic scene?' and 'what are their remits and visions of legacy?' (i.e., polity). The chief diagnostic questions included 'what are the underlying concerns behind the main sport legacy promises?' and 'what modes of governance were employed to shape the state-society 
exchange?' (i.e., politics). The evaluative question addressed was 'what policy instruments were used to deliver the legacy promises and to what effect?' (i.e., policy).

The focus of the qualitative analysis was on defining the concept of legacy governance and mapping the range, nature and dynamics of the actors, modes of governance and the policy instruments used in constructing the legacy at national level. The study utilized secondary sources of information including policy documents, statements and archival records published by various governmental and nongovernmental agencies, or a total of over 120 documents. In particular, it focused on eight newly-emerged institutions on the UK Olympic legacy scene including the Olympic Delivery Authority (ODA), the Sport Legacy Delivery Board (SLDB), Government Olympic Executive (GOE), the Commission for Sustainable London (CSL), the Legacy Trust, the London Employment and Skills Task Force (LEST), the Host Boroughs Strategic Unit (HBSU) and Podium. Those institutions were created as a direct result of awarding the Olympics to London and the UK Government's Olympic promises, and provide a unique opportunity to study their role in shaping the governance of this event's legacy. The IOC Executive Board' (1921-1979) and Sessions' (1894-2009) minutes and the Technical Manual on Olympic Games Impact (IOC, 2009) were also examined in order to determine the evolution of the global legacy thinking and its relation with the London 2012 sport legacy visions.

A limitation of this study has been that it mainly considers the top-down approach to legacy, as constructed by various governmental agencies, and only partially takes into account the bottom-up approach which involves the interpretations and actions of different community groups, activists and research institutes. 


\section{Legacy governance as polity}

This section maps out the emerging new national institutional actors as a direct result of implementing the Olympic legacy promises. The institutional, or governance dimension, has been established as the fourth dimension of sustainable development alongside the social, environmental and economic. It puts greater emphasis on the social equity and participative aspects of delivery and the democratic and political processes for achieving this (Spangenberg, 2004). Girginov \& Hills (2009) documented the political process of constructing sustainable Olympic sports development legacy and pointed out that it is premised on three common assumptions - creation of intersubjective meanings which go beyond individual beliefs, participation, and a mandate for action. In combination, these three assumptions have initiated the process of institutionalization of legacy so the institutionalized world of Olympic legacy creation can be experienced as an objective reality. Subsequently, the Olympic legacy framework turned the idea of sustainable sports development into an enterprise rationalising and legitimising its major stakeholders, organisations concerned with monitoring and measuring the legacy and a myriad of delivery partners.

The new institutional arrangements, however, have been added to an already complex governance landscape of London, which Newman (2007) described as one of changing institutions and recurrent experiment. Newman's comment touches at the heart of sustainable governance as it challenges one of its main premises concerned with human capacity to predict the future and to deal with uncertainties. 
Hardman \& Scott (2010: 177) argued that "the patterns of state activity associated with agency creation are rooted in a deeper dynamic of expansion and differentiation of state activity". They proposed a categorization of the modes of state action including developmental, regulatory, adjudicatory and moral advocacy, which were used to further unpack the emerging Olympic institutional legacy landscape and responsibilities. The developmental mode of state action concerns generating and managing economic development; the regulatory involves the creation of public authoritative bodies to regulate areas of economic and social life, as well as delegating power to private bodies, who under license can oversee professional activities with a public interest dimension to them; the adjudicatory function of the state deals with conflict resolution and grievances by resorting to law; and the moral advocacy involves both regulating personal morality and creating a climate of moral values.

Girginov \& Hills (2008) identified eleven major international and national developers on the Olympic legacy scene. At the time of writing the Statutory Register, which is a comprehensive regulatory mechanism kept by the London Organising Committee of the Olympic Games (LOCOG), contains 127 organizations authorized to deal with the Games, of which 9 multinational companies, 26 domestic commercial companies, 4 licensees, 3 broadcasters and 85 non-commercial organisations. The UK Government has further institutionalized and bureaucratized the legacy scene by establishing 11 government boards designed to develop different aspects of 2012 legacy, thus further reinforcing the regulatory mode of state action.

[Table 1 about here] 
Table 1 shows the main agencies in each of the four categories of state action and their functions in relation to the Olympics. The strategic decision making body with ultimate responsibility for all Olympic matters including legacy commitments is the Olympic Board. This is a public-voluntary body, which comprises a temporary limited company, LOCOG, two public bodies- the Great London Assembly (GLA) and the Government, and a voluntary actor, the British Olympic Association (BOA). The developmental action of the state is carried out by a mix of public, private and charitable agencies, all of which were initiated by the state. A public body, the ODA was charged with the delivery of the infrastructural legacy of the Games, the LEST- a public-private partnership, with tackling London's worklessness problem and improving the productivity of its workforce, and a charitable organization, the Legacy Trust, with supporting sporting and cultural activities for all. Since the regeneration of East London was a major concern of the Games, a special Host Boroughs Strategic Unit (HBSU) was established in order to lead the local regeneration efforts.

The high public stakes in the Olympics dictated that the regulatory action was assigned to an Olympic and Paralympic Games Cabinet Committee (Government Olympic Executive, GOE) with ministerial responsibilities. Its mandate is mainly regulatory ensuring public control over budgetary and delivery matters. The GOE is also closely involved with the Sport Legacy Delivery Board, which is made up of senior representatives from 17 public and voluntary organizations including eight government departments and agencies. However, it is not clear how effectively this body has been fulfilling its role since it only met twice in five years-once for setting its terms of reference and the second time without the Minister, its Chair (Moynihan, 2010). The role 
of a 'critical friend' with regard to the sustainable dimension of the Games was given to an independent Commission for Sustainable London (CSL). Its function is to ensure that every aspect of the planning and delivery of the Games complies with the principles of sustainability, but it has no jurisdiction over the myriad of sport legacy developers.

Finally, the moral advocacy action was manifested through the creation of Podium, a public further and higher education unit for the Games. The role of Podium is to mobilize support and to encourage public engagement within the educational sector. This is to be achieved mainly by forging networks of institutions and groups in pulling resources and maximizing effects. Public participation is a central tenet of sustainability as advocated by the Melbourne Principles for Sustainable Cities (UNEP, 2002). Podium's explicit function has been to deliver the central, yet the most elusive function of the Games, to inspire young people. However, because Podium is funded by the Higher Education Council of England, it has no clout over the rest of the UK. There are no specifically designed new organizations to perform adjudicatory actions. The Olympic properties in the UK are protected by the Olympic and Paralympic Games Act (2006) and all business and promotional associations with the Games have been controlled by LOCOG and the BOA. However, the Public Service Agreement (PSA) framework has authorized Sport England and UK Sport to penalize National Governing Bodies of sport (NGB) for failing to meet delivery targets by withdrawing funding. Although the UK Government allowed the involvement of private and charitable actors, the predominant mode of political steering of Olympic legacy has been hierarchical and top-down including legal and administrative sanctions. The accountability function in relation to 
sustainability was delegated to the CSL which is funded by those it is supposed to supervise.

\section{Legacy governance as politics}

Understanding governance as politics requires examining actor constellations and power relations between political actors involved in political and social steering of sustainable Olympic sport legacy. The legacy concept reflects the democratization of Olympic polity, which involves a complex interplay between, on one hand, global forces including the IOC, multinational companies that sponsor the Olympics and media organizations promoting them, and on the other, states, societies and cities hosting the Games. Commenting on 'the Olympic growth machine' Surborg, Wynsberghe and Wyly (2008: 342) expressed that "like all mega-events, the Olympics are almost exclusively urban phenomena that require large public and private investments". Those investments, the authors continue, "play a critical role in tying local processes into wider economic circuits-circuits that are not simply transnational, but transnationally competitive and recurrent as cities vie to host high profile events, gatherings and spectacles".

The concept of Olympic legacy was evoked as a viable alternative designed to compensate for the negative propensities of capitalist growth through the reconstruction of social order by tackling class, poverty, gender and age inequalities. MacRury's (2008) treatment of Olympic legacy as a commodity and gift posits an important point concerning governance. He suggests that while the commodity form involves cost-benefit economic calculations, the gift form concerns the affective sociality and entails relations of engagement and reciprocity between parties. As a result, each form promotes different 
modes and levels of governance aiming at balancing the interests of the state, the market and society. At the beginning of 2010 glaring discrepancies between central and local legacy visions emerged and undermined two of the central premises of governance -its shared values and trust. The government informed the five Olympic host boroughs that they were not going to get any legacy funding for failing to submit their plans and the ODA budget had already been allocated. This prompted a strong reaction from the Host Borough Unit's director Roger Taylor (Morethangames, 2010):

It is the responsibility of the national Government but they made absolutely no effort to consider legacy until the [five] boroughs took matters into their own hands. Nobody was going to do anything about it but we are still of the firm view that it's a national responsibility. And we've just put together a coherent, exciting articulation on what needs to be done to breathe life into the promises made during the Olympic bid.

The challenges posed by striking the balance between local and global interests are considerable given that the ODA and LOCOG are expected to offer up to 75,000 Games-related contracts to various local, national and international companies worth over $£ 6$ billion. As Marcuse (2005, cited in Surborg et al, 2008: 353) put it

specific groups within a city promote policies of competition; specific political leaders are concerned to attract business and make taxation policies attractive; not everyone in a city but specific growth coalitions seek growth; a city does not compete for the Olympics, a city's governmental leaders do, with the support of certain groups within it; others often object mightily. 
Gold \& Gold's (2009) analysis of the evolution of the London Olympic bid and those of its competitors, as well as the Department of Communities and Local Government's reports (Keogh, 2009, OECD-LEED, 2010) supports the above comment. Staging the Games involves two interrelated costs-operational and capital. The operational costs are needed to service athletes and officials in the run up to and during the Games. Those funds are raised by the IOC mainly through two global flows of capital in the form of a global sponsorship programme and the sales of worldwide broadcasting rights. Together, these two sources generated US $\$ 4,960$ billion for the Olympic Movement in the 2009-2012 quadrennial (IOC, 2010). The capital or developmental costs is generated mainly through the mobilization of public funding, which arguably should address local concerns. As Horne \& Manzenreiter, (2006: 18) observed "sports megaevents have been largely developed by undemocratic organizations, often with anarchic decision-making and a lack of transparency, and more often in the interests of global flows rather than local communities. In this respect they represent a shift of public funds to private interests". Poynter (2006: 10) echoed this view with regard to the London 2012 Olympic bid, which "rested extensively on state infrastructure investment; capital costs that are distinct from operating costs. In relation to the latter, it is estimated that around seventy percent of the costs will be supported by public funds". At the time of writing the public capital costs of the Games amount to $£ 9.325$ billion (DCMS, 2010a).

The UK Government's justification for backing the London bid was a classic example of state-society exchange - a massive investment of public funds in return for sustainable cultural, economic and sporting legacy for the whole country, and a mandate for action. A pattern has emerged in the exchange: while predominantly private actors 
were involved in the construction of Olympic venues and infrastructure (i.e., commodity form), the state preferred partners in the governance of sport legacy (i.e., gift mode) have been public and voluntary actors.

\section{Legacy governance as policy}

Normative concepts promote certain visions about the future and suggest the best means to achieve them, thus raising the question whose visions should be promoted and how these should be implemented. Jordan (2008: 25) illustrated the relationship between visions of sustainable development and their implementation with the United Nations' one page 2002 Johannesburg political Declaration on Sustainable Development and a sixty-seven-page Plan for Implementation. The first page of this plan notes that "good governance within each country and at the international level is essential for sustainable development". The UK Government (DCMS, 2007) eight-page Our Promise for 2012 and the eighty-page Before, During and After (DCMS, 2008) action plan offer a road map for implementing the five (and now six, including disability, DCMS, 2010b) substantial promises. It makes a single reference to sport and physical activity governance structure, and offers no further detail about the principles on which governance should be based. The action plan also makes it clear who is responsible for designing the legacy visions “these promises provide a framework for organizations and individuals across the UK. We are inviting them to play their part in fulfilling the potential of the Games, and here set out the first steps we have taken to realize our legacy ambitions" (DCMS, 2008: 3). This statement is indicative of the preferred negotiation policy style when forging 
consensus in the relationship between the British government and society (Howlett \& Ramesh, 1995).

The rest of the paper follows Trieb et al's (2007) four modes of governance to analyze the policy instruments employed for the delivery of sustainable Olympic sports development legacy. There has been a limited deployment of the coercive mode of governance. The only explicit and highly prescriptive instrument has been the London Olympic Games and Paralympic Games Act (2006) regulating the work of the ODA and the Regional Development Agencies, as well as the use of Olympic insignia. However, the speed of passing the act through the Parliament in order to honor a commitment made to the IOC has been unprecedented. The hasty compliance with requirements imposed by a non-accountable international organization, that is the IOC, violates a fundamental principle of sustainability concerning public participation.

The second mode of legacy steering is voluntarism, which has marked most of the instruments deployed. A prime example of voluntary steering, which links up the main legacy promise of the Olympics with the coercive mode of governance, is the 'Inspire' programme promoted by LOCOG. It was created to officially recognise outstanding noncommercial sport, as well as other projects and events inspired by the Games, but does not allow the use of Olympic insignia . 'Inspire' has become a powerful instrument in what Fairclough (200: 157) describes as 'cultural governance', which "implies an increased importance for discourses in shaping the action - managing culture means gaining acceptance for particular representations of the social world, i.e., particular discourses". The UK Government has been very explicit in its Olympic ambitions with regard to young generation: "we will transform the lives of young people through sport"

\footnotetext{
* By mid April 2011, over 500 projects were awarded the Inspire mark in the UK.
} 
(DCMS, 2008: 3). 'Inspire' promotes a discourse about how organizations should operate and how individuals should act. The 'inspired person' therefore, is not simply an active sports person, but one who is creative, sharing, and possessing leadership qualities as only the very best get recognized and the 'Inspire' badge.

The third mode of governance, targeting, has been heavily employed in legacy construction. It uses non-binding but detailed recommendations concerning the activities of various legacy actors. Targeted governance first identifies groups and sectors from society or issues subject to interventions and then devises policy instruments for introducing change. Examples of flagship interventions include making all 5 to 16 yearolds more physically active by introducing five hours of sport weekly; engaging the 'hard to reach youth' through sport volunteering; removing barriers to participation through long-term support and the provision of information (e.g., Everyday Swim), and enhancing the role of the further and higher education in the Games (e.g., Podium). While some national initiatives received long-term state support, most policy interventions have been project-based and premised on a capacity-building approach, thus with limited lifespan, and logistical and financial support attached to them (Girginov \& Hills, 2008).

Finally, the framework regulation mode of governance carries a law-binding spirit but still allows for leeway in implementation. The IOC framed the legacy as a three-stage process: a framework developed by the IOC, a vision produced by the candidate city, and implementation secured by the Organising Committee of the Games (i.e., LOCOG). The UK Government and LOCOG's visions of legacy have resulted in developing an implementation framework, which not only fits within the IOC global framework, but is far more comprehensive, sophisticated and ambitious. While technically the governance 
structure outlined in the action plan talks about "legacy vision" (DCMS, 2008: 23), the same document makes it clear that together with the Government promises it "provides the framework for thinking and acting" (p.3).

A central policy instrument in the framework regulation mode of governance has been the Public Service Agreement 22 (PSA). It is underpinned by the philosophy of New Public Management (Flynn, 1997) and its purpose is to ensure that the Government sport promises are turned into tangible and measurable legacy results. The key performance indicator (KPI5) for measuring the success of promise one 'Creation of a world-class system for Physical Education (PE) and sport' is the "percentage of 5-16 year olds participating in at least 2 hours a week of high-quality PE and sport at school and the percentage of 5-19 year olds participating in at least 3 further hours a week of sporting opportunities" (HM Treasury, 2007: 6). While this is an admirable objective first set in 2002, it could also be argued that one does not need the Olympics in order to make it happen. The specific delivery mechanisms include a range of flagship, and other programmes, demonstration projects, financial incentives such as discount rates and national promotional campaigns, such as 'change4 life'.

However, the PSA not only introduced a framework for legacy delivery, but a whole new management culture, an essential part of which has been regular downwards monitoring and upwards reporting.

Legacy institutions, modes of governance and policy instruments are mutually constructive: since the legacy framework establishes objectives and indicators designed to measure some form of development, the successful imposition of every new indicator creates a new group of 'underdeveloped'. The governance of Olympic sport legacy has 
been institutionalized through a range of new mainly public, but also public-voluntary bodies led by the GOE with an over 100 strong staff. The significance of the institutionalisation of governance is in the purpose of those institutions which exist to control human conduct by setting up predefined patterns of conduct (Berger \& Luckmann, 1971). Participation targets' setting, therefore, is only natural for legacy developers. The problem is that this has not been accompanied by adequate measures for strengthening voluntary sport structures with finance and training so they can take on the extra coaching, participation and partnership that is loaded on to a system already struggling for volunteers and tasks that look and feel evermore like substitution for paid professionals. Yet no DCMS, Sport England, LOCOG or the Mayor for London's strategic documents even mention this let alone propose policies to help. Instead, there have been more demands to modernize and professionalize. Mike Collins, a long-term sport policy analyst, sees this as a systemic failure of governance in UK sport (personal communications, 15 May 2010).

\section{Conclusions}

Sustainable Olympic sport legacy is a prospective concept concerned with shaping the future of society, and in the case of the London 2012 Olympics, with transforming the lives of young people in particular. The pursuit of sustainable legacy presented all parties with a critical governance issue and urged reconsidering the relationship between the state, society and global actors. Concerns with Olympic legacy provided a new policy space for interactions between the state, the market and society and helped expand the governmentalization of the British state. Houlihan and 
Groeneveld's (2010) analysis of social capital and governance of sport in Europe supports this conclusion.

Table two shows the four modes of Olympic sport legacy governance, the leading institutions and the preferred policy instruments employed, and together with the text below provide a summary of the main contextual, diagnostic and evaluative questions addressed by this study. The context of national legacy was largely determined by public actors: four of the eight new legacy actors were public bodies, while the rest had various degrees of state involvement. The British state formulated the main legacy visions and saw the transformation of young people's lives and establishing the rules of the legacy game as its main responsibility. This finding challenges a major tenet of governance in that far from 'hollowing out' the state (Rhodes, 2007) it was 'rolled out'. Grix and Phillpots (2011) echoed this view and provided evidence that the governance of UK sport rests on asymmetrical power relations and resource dependency between policy makers (the Government) and policy takers (stake-holders). The net result was that although the British state did not specifically take on itself to govern Olympic legacy, it promoted institutional conduct that was consistent with its legacy visions.

\section{[Table 2 about here]}

In answering the main diagnostic question the study examined four main modes of governance employed in constructing Olympic legacy. Central to all modes of governance are the notions of public participation, collective action, accountability and transparency. The lack of wide public consultations in the delivery of the Olympic Games has been well documented (Adranovich et al, 2001, Lenskyj, 2008). Although the public consultation process in London has been much more transparent compared to previous 
Games, key decisions still remain highly selective and privileging the interests of a few powerful competing elites. Rhodes (2007: 1250) described this political elitism as "the oligopoly of the political market place". The importance of legacy ownership has been of particular concern for local governments in East London (London Assembly, 2010). A new economics foundation report (Ryan-Collins \& Sander-Jackson, 2008) proposed an alternative model of ownership of London Olympic legacy, which takes a true local participatory view.

The framework regulation mode of governance has been of particular significance for creating sporting legacies. In combination with the targeting mode of governance it provides action with specific focus by linking the intent to transform young people's lives with the agencies responsible for that. The UK Government's legacy plans established a trusteeship which binds the intent to transform young people with the process of legacy delivery. Three particular modes of state action employed in social and political steering were documented including developmental, regulatory and moral advocacy. Those actions helped institutionalize the legacy enterprise and broadly defined the responsibilities of the state and society.

The evaluative questions concerned what policy instruments were used in the governance of Olympic legacy and to what effect. The main policy instruments in the four modes of governance have been proposed, designed and implemented by state actors and have regulatory character. MacRury and Poynter (2009: 320) echoed this conclusion: "the legacy plan is heavily pre-occupied with the nomination, delegation and redistribution of 'legacy' responsibilities across the various stake holding bodies while popular or local participation is accorded a marginal or merely 'consultative' status 
consistent with the 'state-centered' mode of governance". This is in contrast with Jordan et al (2005: 481) assertion that "governance is characterized by a growing use of nonregulatory policy instruments", but in line with the new UK Government legacy plan that "truly vibrant sporting provision should not be subject to multiple conditions set within Whitehall" (DCMS, 2010c: 2).

A policy instrument used within the framework regulation mode was sanctions against non-delivery of agreed targets. The logic of sanction imposition has been based on two key premises including agents' capacity to predict the future and the existence of a casual relation between growth/investment and impact. It is grounded in a belief of sustainability as a linear process which links economic growth to social progress. It attributes functions to sport legacy which are rooted in a positivist belief that social life can be improved by deliberate interventions based on scientific rationality and knowledge. Previous studies on the relationship between Olympic investments and sport for all in host cities reported the lack of such links (Brown \& Massey 2001, Cashman, 2006, Coalter, 2004, Wang \& Theodoraki, 2007).

What the cause-effect logic fails to recognize is the holistic nature of sustainable development. As Walton, Longo \& Dawson's (2008) study of Olympic legacy outside London suggests, we need to consider different topographies and recipients of legacies. The Host Boroughs Strategic Legacy Plan (HBSU, 2009) makes another powerful point that the delivery of any Olympic legacy will be contingent on enhancing health and wellbeing, housing, education, employment and arresting anti-social behaviour. The elimination of poverty has been accepted as a central tenet of sustainability (Jordan, et al, 2005) and sports development programmes (Hylton et al, 2007). It has also been 
enshrined in the first of the ten Melbourne Principles for Sustainable Cities (UNEP, 2002), developed after the 2000 'green' Sydney Olympics, which specifically emphasized the role of governance, but London has not adopted those principles. Collins (2010) provided convincing evidence for the adverse effects of social inequalities on sport development policies in the UK, and challenged the feasibility of DCMS' chosen target to use the Olympics to raise sports participation by 2016 to the level of Finland, one of the most equal societies in the world.

In conclusion, the governance of sustainable Olympic sports legacies urges the IOC to specifically acknowledge the developmental needs of the host country and city and to encourage the development of peculiarly local legacies. Holden et al (2008) demonstrated the difference between global and local legacies with regard to the 2010 Vancouver Winter Olympics. This entails reversing the logic of the current legacy thinking, which moves from an IOC framework to LOCOG vision and local delivery, to locally informed development strategies supported by the IOC through a developmental design of the Olympic Games informed by sustainable principles. The introduction of the notion of sustainable sport development legacies offers a rare opportunity to constructively challenge the Olympic tradition in the face of the need to democratize the governance of the Games and to enhance their contribution to the building of sustainable cities and a sustainable world. 


\section{References}

Adranovich, G., Burbank, M. and Heying, C. (2001) Olympic Cities: Lessons Learned from Mega Events Politics, Urban Affairs, 23 (2): 113-131.

Berger, P. and Luckmann, T. (1971) The social construction of reality. A treatise in the sociology of knowledge. London: Penguin Books.

Boron, S. and Murray, K. (2004) Bridging the unsustainability gap: A framework for sustainable development, Sustainable Development, 12 (2): 65-73.

Brown, A. and Massey, J. ( 2001) Literature Review on the impact of major sporting events: the Sports development impact of the Manchester 2002 Commonwealth Games Manchester: Manchester Metropolitan University Institute for Popular Culture.

Brubank, M., Andranovich, G. and Heying, C. (2001) Olympic Dreams. The Impact of Mega-events on Local Politics. London: Lynne Rienner Publishers.

Cashman. R. (2006) The Bitter-Sweet Awakening. The Legacy of the Sydney 2000 Olympic Games. Sydney: Walla Walla Press.

Chappelet, J-L. and Kübler-Mabbott, B. (2008) The International Olympic Committee and the Olympic system: the governance of world sport. London: Routledge.

Coalter, F. (2004) 'Stuck in the blocks? A sustainable sporting legacy?', In A. Vigor and M. Mean (eds.), After the gold rush? The London Olympics London: Institute for Public Policy Research/Demos.

Collins, M., (ed.), (2010) Examining Sports Development. London: Routledge.

DCMS (Department of Culture, Media \& Sport). (2010a) London 2012 Olympic and Paralympic Games Annual Report, February 2010. London: DCMS. 
DCMS. (2010b) London 2012: A legacy for disabled people: Setting new standards, changing perceptions. London: SCMS.

DCMS. (2008) Before, during and after: making the most of the London 2012 Games. London: DCMS.

DCMS. (2007) Our promise for 2012: How the UK will benefit from the Olympic and Paralympic Games. London: DCMS.

Dresner, S. (2003) The principles of sustainability. London: Earthscan.

Enoch, N. (2010) 'Towards a contemporary national structure for youth sport in England', in M. Collins (ed.), Examining Sports Development (pp. 45-71). London: Routledge.

Fairclough, N. (2000) New Labour, New Language? London: Routledge.

Flynn, N. (1997) Public Sector Management. Hemel Hempstead:Prentice Hall/Harvester.

Frey, M., Iraldo, F. and Melis, M. (2007) 'The Impact of Wide-Scale Sport Events on Local Development: An Assessment of the XXth Torino Olympics Through the Sustainability Report'. Paper presented at RSA, Region in Focus? International Conference, Lisbon, 2-5 April.

Furrer, P. (2002) Sustainable Olympic Games. Bollettino della Societa Geografica Italiana Series XII, 7 (4).

Girginov, V. and Hills, L. (2009) The political process of constructing a sustainable London Olympics sports development legacy, International Journal of Sport Policy, 1 (2): 161-181. 
Girginov, V. and Hills, L. (2008) The 2012 London Olympic Games and participation in sport: understanding the link. The International Journal of the History of Sport, 25(14): 2091-2116.

Gold, J., \& Gold, M. (2009) Future Indefinite? London 2012, the Spectre of Retrenchment and the Challenge of Olympic Sports Legacy, The London Journal, 34 (2): 179-196.

Grix, J., \& Phillpots, L. (2011) Revisiting the 'Governance Narrative'. 'Asymmetrical Network Governance' and the Deviant Case of the Sports Policy Sector, Public Policy and Administration, 26 (1): 3-19.

Hardiman, N., and Scott, C. (2010) Governance as Polity: An Institutional Approach to the Evolution of State Functions in Ireland, Public Administration, 88 (1): 170189.

HBSU. (2009) Olympic and Paralympic Legacy: Strategic Regeneration Framework, London: HBSU.

Henry, I. (2007) Transnational and comparative research in Sport: globalisation, governance and sport policy, London: Routledge.

HM Government. (2007) Securing the future: delivering the UK sustainable development strategy. London: HM Government.

HM The Treasury. (2007) PSA Delivery Agreement 22: deliver a successful Olympic Games and Paralympic Games with a sustainable legacy and get more children and young people taking part in high quality PE and sport. London: HM Government. 
Holden, M., MacKenzie, J. and VanWynsberghe, R. (2008) Vancouver's promise of the world's first sustainable Olympic Games, Environment and Planning C:

Government and Policy, 26: 882-905.

Houlihan, B., and Groeneveld, M. (2010) Social Capital, Governance and Sport (pp. 120), in M. Groeneveld, B. Houlihan and F. Ohi (eds.). Social Capital and Sport Governance in Europe, London: Routledge.

Horne, J. and Manzenreiter W. (2006) 'An Introduction to the Sociology of Sports Megaevents'. Sociological Review Supplement. 2, Oct: 1-24.

House of Commons, Culture, Media and Sport Committee (HC CMS Committee), (2007) London 2012 Olympic Games and Paralympic Games: funding and legacy, Second Report, volume I (HC 69-1), London: HMSO.

Howlett, M. and Ramesh, M. (1995) Studying Public Policy: Policy Cycles and Policy Subsystems, Oxford: Oxford University Press.

Hoye, R. (2007) Sport Governance, London: Elsevier.

Hums, M. and MacLean, J. (2004) Governance and Policy in Sport Organizations. Scottsdale, Arizona: Holcomb Hathaway Publisher.

Hylton, K., Bramham, P., Jackson, D. and Nesti, M. (2007) Sports Development: Policy, Process and Practice, ( $2^{\text {nd }}$ ed.). London: Routledge.

IOC. (2010) Marketing File. Lausanne: IOC.

IOC. (2009) Technical Manual on Olympic Games Impact. Lausanne: IOC.

IOC. (2007) Olympic Charter. Lausanne: IOC.

IOC. (2004) Olympic Charter. Lausanne: IOC. 
Jordan, A. (2008) The governance of sustainable development: taking stock and looking forwards, Environment and Planning C: Government and Policy, 26: 17-33.

Jordan, A., Wurzel, R. and Zito, A. (2005) The Rise of ‘New' Policy Instruments in Comparative Perspective: Has Governance Eclipsed Government?, Political Studies, 53: 477-496.

Keogh, L. (2009) London 2012 Olympic legacies: Conceptualising legacy, the role of Communities and Local Government and the regeneration of East London. London: Department of Communities and Local Government.

Leopkey, B. (2009) The Historical Evolution of Olympic Games Legacy, 2008 Post Graduate Grant Final Report. Lausanne: Olympic Study Centre.

Lenskyi, H. (2008) Olympic Industry Resistance. Challenging Olympic Power and Propaganda, New York: SUNY Press.

LOCOG. (2009) Towards a One Planet 2012, (2 $2^{\text {nd }}$ ed).: LOCOG: London.

London Assembly. (Economic Development, Culture, Sport and Tourism Committee). (2010) Legacy Limited? A review of the Olympic Park Legacy Company's role. London: Greater London Authority.

MacAloon, J. (2008) 'Legacy' as managerial/magical discourse in contemporary Olympic affairs. The International Journal of the History of Sport, 25(14): 20602071.

MacRury, I. and Poynter, G. (2009) Olympic Cities and Social Change (pp.303-327), in G. Poynter, \& I. MacRury (eds.). Olympic Cities: 2012 and the Remaking of London, Furnham: Ashgate.

MacRury, I. (2008) Re-thinking the Legacy 2012: the Olympics as commodity and gift, $21^{\text {st }}$ Century Society, 3 (3): 297-312.

Mol, A. (2010) Sustainability as global attractor: the greening of the 2008 Beijing Olympics, Global Networks, 10 (4), 510-528. 
Morethangames. (2010) "Five Olympic host boroughs criticise Government over legacy plans", Retrieved from http://www.morethanthegames.co.uk/summersports/158231-five-olympic-host-boroughs-criticise-government-over-legacy-plans, March $15^{\text {th }}, 2010$.

Moynihan, L. (2010) Presentation on the Olympic Progress Debate - House of Lords, $5^{\text {th }}$ January 2010.

Newman, P. (2007) "Back the Bid": The 2012 Summer Olympics and the Governance of London, Journal of Urban Affairs, 29 (3): 255-267.

OECD-LEED. (2010) Local Development Benefits from Staging Global Events: Achieving the Local Development Legacy from 2012. London: Department of Communities and Local Government.

Owen, K. (2001) The local impacts of the Sydney 2000 Olympic Games: Processes and Politics of Venue Preparation. Monograph Series (3). Sydney: UNSW.

Peters, G. and Pierre, J. (1998) Governance without Government? Rethinking Public Administration, Journal of Administration Research and Theory, 8 (2): 223-243.

Poynter, G. and MacRury, I. (eds). (2009) Olympic Cities: 2012 and the Remaking of London, Furnham: Ashgate.

Poynter, G. (2006) From Beijing to Bow Creek. Working papers in Urban Studies. London: University of East London.

Preuss, H. (2007) The Conceptualisation and Measurement of Mega Sport Event Legacies, Journal of Sport \& Tourism, 12 (3/4): 207-227.

Rhodes. A. (2007) Understanding Governance: Ten Years On, Organisation Studies, 28 (08): 1243-1264 
Ritchie, J. and Spencer, L. (2000) 'Qualitative data analysis for applied policy research' (pp.305-331), in M. Huberman \& M. Miles (eds), The Qualitative Researcher's Companion. London: Sage.

Roche, M. (2009) Putting the London 2012 Olympics into perspective: the challenge of understanding mega-events, $21^{\text {st }}$ Century Society, 3 (3): 285-291.

Ryan-Collins, J. and Sander-Jackson, P. (2008) Fool's Gold: How the 2012 Olympics is selling East London short, and a 10 point plan for a more positive local legacy, New London: Economics Foundation.

Shoval, N. (2002) A new phase in the competition for the Olympic gold: the London and New York bids for the 2012 Games, Journal of Urban Affairs, 24 (5): 583-599.

Smith, A. (2007) Large-scale events and sustainable urban regeneration: key principles for host cities, Journal of Urban Regeneration and Renewal, 1 (2): 178-190.

Spangenberg, J.H. (2004) Reconciling Sustainability and Growth: Criteria, Indicators, Policies, Sustainable Development 12: 74-86.

Surborg, B., VanWynsberghe and Wyly, E. (2008) Mapping the Olympic growth machine. Transnational urbanism and the growth machine Diaspora. City, 12 (3): 341-355.

Trieb, O., Bähr, H. and Falkner, G. (2007) Modes of governance: towards a conceptual clarification. Journal of European Public Policy, 14 (1): 1-20.

UNEP. (2002) Melbourne Principles for Sustainable Cities. Nairobi: UNEP.

Walton, H., Longo, A. and Dawson, P. (2008) A Contingent Valuation of the 2012 London Olympic Games, Journal of Sports Economics, 9 (3): 304-317. 
Wang, W. and Theodoraki, E. (2007) Mass sport policy development in the Olympic City: the case of Qingdao - host to the 2008 sailing regatta, The Journal of the Royal Society for the Promotion of Health, 127 (3): 125-132. 
Table 1.

New institutional examples of the four modes of state action in Olympic legacy

\begin{tabular}{llll}
\hline $\begin{array}{l}\text { Mode of state } \\
\text { action }\end{array}$ & New UK agencies & $\begin{array}{l}\text { Functional } \\
\text { classification }\end{array}$ & Sector \\
\hline Developmental & ODA & Delivery & Public \\
& HBSU & Delivery & Public \\
& LEST & Delivery & Public-private \\
& Legacy Trust & Funding & Voluntary \\
Regulatory & GOE & Regulatory & Public \\
& SLDB & Regulatory & Public-voluntary \\
& CSL & Advisory/consultative & Independent \\
Moral advocacy & Podium & Advisory/consultative & Public \\
Adjudicatory & N/A & & \\
\hline
\end{tabular}

Table 2.

Modes of governance, institutions and policy instruments in delivering sustainable Olympic sports legacy

\begin{tabular}{lll}
\hline Mode of Governance & Institutions & Policy instruments \\
\hline Coercive & ODA & Tenders, contracts, \\
& & legislation \\
Voluntarism & 'Inspire', road shows, \\
& & public registers, financial \\
Targeting & incentives, policy discourse \\
& Podium, DCMS, Legacy & Road shows, projects, posts \\
& Trust & creation, flagship \\
& & programmes, policy \\
Framework regulation & DCMS, GOE, CSL & discourse \\
& & PSA, upward reporting, \\
& & surveys, \\
& & reports/recommendations \\
\hline
\end{tabular}

